УДК 78.01

DOI https://doi.org/10.31723/2524-0447-2019-29-2-7

\author{
Антон Викторович Ерецкий
}

ORCID: 0000-0002-9641-0113

соискатель кафедры истории музыки и музыкальной этнографии

Одесской национальной музыкальной академии имени А. В. Неждановой

anton.yeretskyy@gmail.com

\title{
ПРОБЛЕМА СООТНОШЕНИЯ ЗВУЧАЩИХ И НЕЗВУЧАЩИХ СТРУКТУР В МУЗЫКЕ: МУЗЫКОВЕДЧЕСКИЙ ПОДХОД
}

Цель статьи - выявить и обобщить свойства незвучащих структур музыкального произведения. Методология работы предполагает взаимодействие музыковедческого и феноменологического подходов в изучении соотношения пульса и ритма в музыке. Научная новизна исследования определяется задействованием положений работ о хроноартикуляционных структурах М. Аркадьева и феноменологического труда А. Лосева, а также исследователей музыкального времени - представителей американской школы музыковедения Дж. Крамера и С. Лангер. Выводы. В результате анализа мы выявили наличие незвучащих структур в произведениях А. Вивальди - в Первой части Концерта для 4-х скрипок и Первой части Второго кониерта из цикла «Времена года», а также в Первой части Первого Бранденбургского концерта И.С. Баха, и пришли к выводу, что в определенной степени любое музыкальное произведение имеет виртуальную форму или является «незвучащим»- $и$ до, и в процессе, и после своего исполнения. По признанию М. Аркадьева, «мы всегда в состоянии отделить то, что может физически звучать, от того, что принципиально не подлежит акустически-звуковому оформлению, оставаясь при этом необходимым и реальным внутренним элементом музыкальной ткани <... $\gg$ [1, с. 34]. В иелом, опора на некоторые положения ученого с их последующим развитием дает возможность предположить существование музыки как в звучащей (очевидной), так и в иной, не звучащей форме, что создает экзистенциальную асимметрию. В проанализированных произведениях А. Вивальди и И.С. Баха был найден «первоначальный импульс», который предстает искомой нами незвучащей структурой. К примеру, начало Первой части Второго концерта из иикла «Времена года» демонстрирует необходимость «внутреннего» исполнения указанной Вивальди паузы, без которой исполнение этого эпизода приводит $\kappa$ иному, не верному художественному наполнению. Незвучащие структуры-иной, скрытый даже для опытных исполнителей, принципиально 
отличающийся от явного уровень экзистенции музыки. Незвучащие сттруктуры, являясь неотьемлемой частью музыки, подобно темной материи космоса обнаруживаемы лишь по косвенным признакам, но реально существуют, составляют основу и непосредственно влияют на музыкально-исполнительский процесс и процесс восприятия музыки. «Незвучащее»-временно-пространственная основа музыки.

Ключевые слова: время, музыкальное время, ритм, нотация, звучащие и незвучащие структуры, экзистенциально-музыкальная асимметрия.

Yeretskiy Anton Vyktorovych, Applicant at the Department of Music History and Musical Ethnography of the Odessa National A. V. Nezhdanova Academy of Music

The problem of relationship of sounding and non-sounding structures in music: a musicological approach

The purpose of the article - to indicate non-sounding structures in music scores. The methodology based on principles of phenomenology which was applied for pulse-rhythm interaction analyses. The scientific novelty of the work determined by combining results of both American and domestic schools of musicology, its synchronization. Conclusions. As a result of the analysis, we revealed the presence of non-sounding structures in the work of A. Vivaldi - in the First part of the Concert for 4 violins and the First part of the Second concert from the cycle "Seasons", as well as the First part of the First Brandenburg Concert by I.S. Bach, and came to the conclusion that, to a certain extent, any piece of music has a virtual form or is "notsounding" - both before, during, and after its performance. According to M. Arkadiev, "we are always able to separate what can physically sound from what is fundamentally not subject to acoustic-sound design, while remaining a necessary and real internal element of musical fabric <... $>$ " $1, p .34]$. In general, reliance on certain positions of the scientist, with its subsequent development, makes it possible to assume the simultaneous existence of music both in sounding (obvious) and in a different, non-sounding forms, which creates existential asymmetry. In the compositions of A. Vivaldi and I.S. Bach that were analyzed, an "initial impulse" was found, which appears to be the non-sounding structure we are looking for. For example, the beginning of the the First part of the Second concert from the cycle "Seasons" dismantles the need for an "internal" performance of the pause indicated by Vivaldi, without which the performance of this episode leads to a different, incorrect artistic content. Non-sounding is another, hidden even for an experienced performer the layer of music existence which principally differ from the explicit one. Those structures are an inalienable part of music just like a dark netter of the space can be detected only by indirect evidence but directly influence music performance and perception processes. Non-sounding is the time-space base of music.

Key words: time, time of music, rhythm, notation, sounding and non-sounding structures, existential musical asymmetry. 
Срецький Антон Вікторович, здобувач кафедри історії музики та музичної етнографії імені $А$. В. Нежданової

Проблема співвідношення структур, що звучать зі структурами, що не звучать, в музиці: музикознавчий підхід

Мета статmі - виявити структури музичного твору, що не звучать. Методологія роботи передбачає взаємодію музикознавчого й феноменологічного підходів у вивченні співвідношення пульсу й ритму в музиці. Наукова новизна дослідження визначається залученням положень робіт про хроноартікуляціонні структури М. Аркад'єва й феноменологічної праці О. Лосєва, а також дослідників музичного часу-представників американської школи музикознавства Дж. Крамера й С. Лангер. Висновки. У результаті аналізу ми вивчили наявність структур, щзо не звучать, у творах А. Вівальді-в Першій частині його Концерту для 4-х скрипок $і$ Першій частини Другого концерту із циклу "Пори року», а також у Першій частини Першого Бранденбурзького концерту Й.С. Баха, й дійшли висновку, що певною мірою будь-який музичний твір має віртуальну форму або є таким, що «не звучить», - $i$ до, $i$ під час, і після свого виконання. За визнанням М. Аркад'єва, «ми завжди в змозі відокремити те, що може фізично звучати, від того, що принципово не підлягає акустично-звуковому оформленню, залишаючись водночас необхідним і реальним внутрішнім елементом музичної тканини <...〉 [1, с. 34]. У иілому, опора на деякі положення вченого з їхнім подальшим розвитком дає можливість припустити одночасне буття музики і в формі, що звучить (очевидній), і в формі, що не звучить, що створює екзистенціальну асиметрію.

У проаналізованих творах А. Вівальді й I.С. Баха був знайдений «початковий імпульс», який постає шуканою нами структурою, що не звучить. Наприклад, початок Першої частини Другого концерту із ииклу «Пори року» демонструє необхідність «внутрішнього» виконання зазначеної Вівальді паузи, без якої виконання иього епізоду приводить до іншого, не вірного художнього наповнення. Структури, що не звучать, - ие інший, прихований навіть для досвідчених виконавців рівень екзистенції музики, що принципово відрізняється від явного. Ці структури, бувши невіддільною частиною музики, подібно до темної матерії космосу підлгають виявленню лише за непрямими ознаками, але реально існують, складають основу й безпосередньо впливають на музично-виконавський процес $і$ процес сприйняття музики. «Те, що не звучить»-часопросторова основа музики.

Ключові слова: час, музичний час, ритм, нотація, структури, що звучать і не звучать, екзистенційно-музична асиметрія.

Актуальность исследования. Один из важнейших вопросов современного музыковедения может быть сформулирован следующим образом: является ли музыка чисто акустическим феноменом или, наряду с этим, она содержит ещё и скрытые, незвучащие, но реально существующие, зашифрованные 
в музыкальном тексте структуры, приобретающие особое значение в процессе исполнения произведения?

Для того, чтобы приблизится к ответу на этот вопрос, необходимо рассмотреть ряд явлений, изучение которых поможет составить представление о незвучащих структурах музыкального текста. К ним относятся: звук, время, пространство, ритм и нотная запись.

Цель статьи - выявить и обобщить свойства незвучащих структур музыкального произведения.

Научная новизна исследования определяется задействованием положений работ о хроноартикуляционных структуpax М. Аркадьева и феноменологического труда А. Лосева, а также исследователей музыкального времени - представителей американской школы музыковедения Дж. Крамера и С. Лангер.

\section{Изложение основного материала.}

Звук

Одним из «строительных материалов» для композитора или исполнителя является музыкальный звук. Даже само этимологическое изучение термина выявляет необходимость дальнейшего углубления: имя прилагательное «музыкальный» указывает на то, что не любой звук можно считать музыкальным.

Строго говоря, с точки зрения акустики, как раздела физики, звуком является распространяющиеся в одной из сред (твёрдой, жидкой, газообразной) колебательных движений частиц в виде волн. Как физическое явление звук может быть описан с помощью определенных характеристик - частоты колебаний, формы колебаний, эффективного звукового давления, величины звукового давления. По своей сути звук - это нарушения равновесного состояния в системе. Согласно закону сохранения энергии, возникновение любого нарушения равновесия системы требует затраты некоего количества энергии. Характер полученных колебаний имеет прямое влияние на время необходимое для возвращения системы в состояние равновесия. В контексте музыки мы в основном говорим о замкнутых системах с четкими границами распространения колебаний. Они совпадают с пространственными границами существования данной конкретной музыки.

Музыкальным или не музыкальным звук становится лишь в момент рефлексии. Тем не менее, учитывая природу звуко- 
вых колебаний и тот факт, что нарушение равновесия затрагивает всю систему и ограничено границами системы, мы видим, что музыка не «умозрительна» и обнаруживает признаки пространственного вида искусства (колебания, объём).

Время

Изучение проблемы музыкального времени сопряжено с некоторыми сложностями, связанными с определением его свойств, а также с тем, как взаимодействуют время (пульс, как воплощение временного континуума в музыке) и ритм. Время, выступающее как параметр, указывающий на скорость возвращения системы в состояние покоя, требует пристального рассмотрения. Являясь одним из фундаментальных атрибутов и свойств материи, время находится вне зоны полного понимания наукой. Сложность определяется отсутствием возможности «прямого» сенсорного или визуального восприятия времени. Одним из законов физики, наиболее красноречиво объясняющих основные законы и свойства времени, есть второй закон термодинамики: в изолированной системе энтропия остаётся либо неизменной, либо возрастает (в неравновесных процессах), достигая максимума при установлении термодинамического равновесия. «Из второго закона термодинамики для таких систем следует, что существует некоторая функция $\mathrm{S}$ (энтропия), монотонно возрастающая до тех пор, пока не достигнет своего максимального значения в состоянии термодинамического равновесия» [7, с. 26]. Вот его формульное воплощение, где энтропия выражена через функцию s. $\frac{d s}{d t} \geq 0$ [7, с. 26]. Из чего следует вывод об однонаправленности и необратимости времени.

«Итак, второе начало термодинамики утверждает, что необратимые процессы приводят к своего рода односторонности времени: положительное направление времени второе начало термодинамики связывает с возрастанием энтропии» [7, с. 26]. Вселенная является идеальным примером замкнутой системы. Ее расширение и остывание является одним из примеров необратимых процессов и, одновременно, показателями однонаправленности времени и его необратимости. Это является основанием считать однонаправленность и необратимость основными, фундаментальными свойствами абсолютного времени.

А. Пигалев отмечает общую тенденцию использования в рассмотрении явления времени терминологии (за редким 
исключением), свойственной для описания пространства: «<..> суть времени стремятся выразить с помощью свойств, присущих пространству» [6, с. 141].

В отличие от восприятия пространства, ни один живой организм не имеет возможности сенсорного восприятия времени. Одним из необходимых навыков для любого живого существа является навык ориентации в пространстве. Фактически, наши органы чувств призваны обеспечить сенсорное отношение «окружающий мир - субъект». Выработка навыка ориентации в пространстве связана с целым рядом дополнительных навыков и умений и, в равной мере, с собранием «библиотеки значений» получаемых извне данных. Тогда как течение, движение времени мы воспринимаем по косвенным признакам, по соотношению скорости появления или свершения событий. В целом, можно выделить две основные традиции восприятия времени - квалитативную (качественную) и квантитативную (количественную) [1, с. 12].

Музыкальное пространство-время обладает такими основными свойствами:

1. Направленность.

2. Необратимость.

3. Непрерывность.

4. Аффективность.

5. Агогичность.

6. Артикуляционность [1, с. 40; 7, с. 25].

Вместе с тем, ряд исследователей склонны считать, что законы музыкального времени отличаются от представлений о бытии времени, как одного из измерений. Например, Дж. Крамер выдвигает довольно спорное положение о том, что музыкальное время реверсивно [14, с. 17]. Исследуя разницу между этими двумя типами времени, философ Сюзан Лангер условно называет музыкальное время “virtual time", а время вселенной, абсолютное время как “clock time” которое она характеризует как "the sequence of actual happenings" [15, с. 43]. В своей работе философ пишет: "Music <...> suspends ordinary time and offers itself as an ideal substitute and equivalent" $[15$, c. 110]. Точка зрения философа сводится к утверждению, что музыкальное время способно приостанавливать обыкновенное время и предлагает его идеальное замещение и равнозначность. Это воззрение верное лишь при условии, что и абсолютное время по сути для нас является виртуальным уже 
в силу того, что характер нашей рефлексии является умозрительным по своей природе. В таком случае время в музыке можно считать вдвойне виртуальным построением. Однако в отличии от рефлексии абсолютного времени, наше восприятие времени в музыке является рефлексией построения, полностью созданного сознанием и волей исполнителя и остающееся в этом же сознании, не смотря на звуковое воплощение. Несмотря на это, данное построение остаётся основанным на свойствах рефлексируемого абсолютного времени. И потому, для того чтобы не уйти в область ложных, лишенных твёрдой почвы размышлений, при выдвижении понимания музыкального времени и его основных свойств, изложенные выше, мы воспользуемся законом ratio cognoscendi (дословно причина знать) в его формулировке А. Лосевым [5, с. 225]. Понимание времени в музыке в своём основании должно иметь свойство абсолютного времени с оглядкой на специфику его музыкально-исполнительского процесса.

\section{Ритм}

Проблематике становления и развития ритма посвящён труд М. Харлапа. Автор предлагает собственную периодизацию стадий развития искусства. Также, в зависимости от представлений эпохи, он акцентирует внимание на зависимости музыкального ритма от стиха, и наоборот, в зависимости от эпохи. Однако, наибольший интерес представляет вопрос отношения lunga и brevis - совершенное (1:3) и несовершенное $(1: 2)$. [6, с. 71]. Интерес к указанному явлению подиктован его влиянием на процесс становления ритмической свободы и вариативности, выявляет исторические предпосылки к появлению определенных ритмических патернов. В рамках данной статьи эпоха Ars Nova интересует нас как эпоха освобождения музыкального искусства от «диктатуры» слова, момент в истории который можно считать началом процесса приведшего к появлению регулярного тактирования.

Труд Харлапа во многом дополняется исследованием В. Апеля, которое в своей основе посвящено вопросу эволюции нотации. Так, во французских лигатурах квадратной нотации мы находим свидетельства значения мелизматики для развития и ритма и нотации.

Учитывая то обстоятельство, что теория ритма на сегодняшний день по-прежнему находится в стадии формирования, мы можем лишь попытаться проследить и описать его 
взаимодействие с пульсом. Семантически мы приравниваем пульс к метру и считаем его олицетворением времени в музыке. Также, в рамках данной статьи, принимаем и продолжаем предложенный М. Аркадьевым принцип градации звуков не на основе протяженности их звучания, но на основании их «веса», то есть метроритмического значения (он предлагает называть их «весомости», что кардинальным образом меняет трактовку взаимодействия пульса и ритма и открывает новые исследовательские горизонты).

Появление регулярного тактирования в районе 1600 года, являющееся естественным результатом развития музыкального искусства, по сути стало революционным событием. Корень этого изменения заключался в качественном сдвиге в эстетико-философском понимании континуумности «временной основы» музыки и, как следствие, в обострении противоречивого по своей природе отношения «пульс-ритм» Несмотря на визуальный эффект разделения музыкальной ткани на сегменты - такты, тактовая черта по своей сути носит объединяющую функцию. Появление непрерывной осевой пульсации явилось необходимым условием для появления искомого феномена незвучащего. Именно в этот момент музыкальное время приобретает явно выраженные необратимость и непрерывность. Аффективность же имеет дуальную природу. С одной стороны, она продиктована гилетической природой музыки [5, с. 215]. С другой, она объясняется конфликтностью пульса, как временной основы и воплощением времени, и ритма. Отношение пульса и ритма носят признаки гравитационности, что при исполнении выражается в виде артикуляции.

Это позволяет нам по-новому взглянуть на взаимодействие пульса и ритма в музыке как на конфликтное по своей сути. При отсутствии теории ритма, этот предложенный Аркадьевым подход позволяет выявить скрытые свойства как пульса, так и ритма через описание их взаимодействия.

Незвучащее

Взаимодействие упомянутых выше времени, ритма и нотной записи образуют искомый феномен «незвучащего». Воспользуемся определением, данным М. Аркадьевым, «незвучащее» в музыке - это то, «...что не подлежит музыкально-звуковому оформлению, оставаясь при этом необходимым и реальным внутренним элементом музыкальной ткани [1, с. 34]. 
Дополнительным доказательством может служить описанное М. Аркадьевым ментальное действие, по сути являющееся мысленным экспериментом: «<..> в сфере нашего внутреннего слуха мы, в принципе, всегда в состоянии воспроизвести всю структуру музыкального процесса... Но, и это является решающим, мы всегда в состоянии отделить то, что может физически звучать от того, что принципиально не подлежит акустически-звуковому оформлению, оставаясь при этом необходимым и реальным внутренним элементом музыкальной ткани <...» [1, с. 34]. Если же обратиться к идее интенциональности сознания Брентано и Гуссерля, то мы получим картину еще более поразительную, при которой только наше сознание и является связующим звеном с внешним миром; Вселенная находится не где-то, а в нашем сознании [4, с. 354].

По всему очевидно, что феномен музыки носит больше внутренний, психический характер бытия, так как любое музыкальное произведение является таковым лишь в следствии рефлексии. Семантическая нагрузка также приобретается только в соответствии с принятой эстетической системой и существует лишь в нашем сознании. Результатом мысленного эксперимента, предложенного Аркадьевым, и изложенных выше доводов, предположим существования музыки как в звучащей (очевидной), так и в иной, не звуковой форме, что создает экзистенциальную асимметрию.

Для выявления незвучащих структур в музыкальном тексте рассмотрим взаимодействие пульса и ритма на примере концерта Вивальди для 4х скрипок с оркестром, 1 часть:

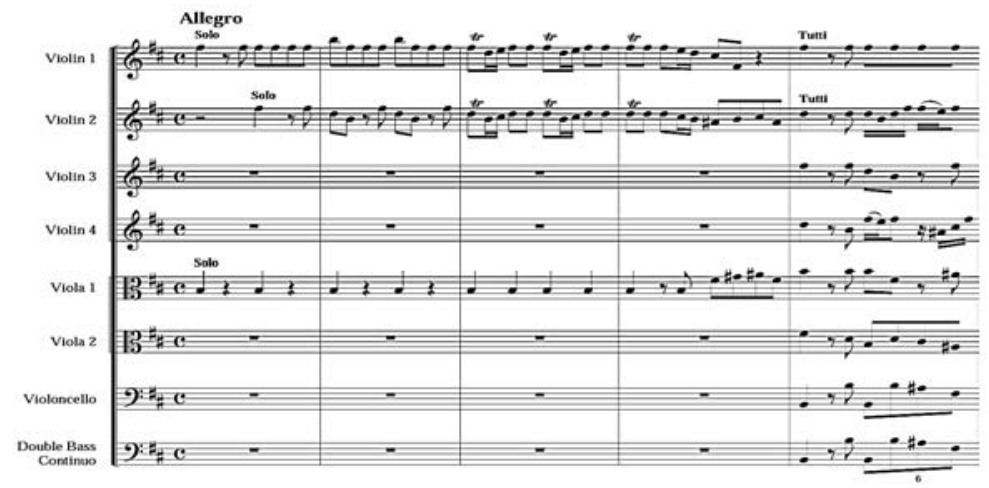


Тема излагается у первой солирующей скрипки и начинается на первую, или тяжелую, долю такта. При учете традиционной для периода барокко «весомости» первых долей такта, становится понятной такое ее выделение. Значимость первой доли подчеркивается также с помощью штрихов (в виду связи барочной музыкальной мысли со спецификой инструментария) - либо более длительным проведением смычка по струне, либо с помощью штриха, который в современной нотации мог бы быть выражен как комбинация spiccato и акцента.

Вступление второй скрипки приходится на третью долю, вторую относительно сильную долю четырёхчетвертного такта. Все это создает упругий ритм с устойчивой акцентировкой на тяжелые доли таков. Однако уже во втором tutti, начинающемся в 12-ом такте, тема изменяется и, по сравнению с довольно прямолинейным по смыслу изложением в начале, приобретает другое значение, начинаясь на третьей доле такта, тем самым приобретая «ямбичность» (по М. Аркадьеву) [1, с. 154]. Одновременно, этот пример косвенно подчеркивает принцип гравитационного взаимодействия между пульсом и ритмом.

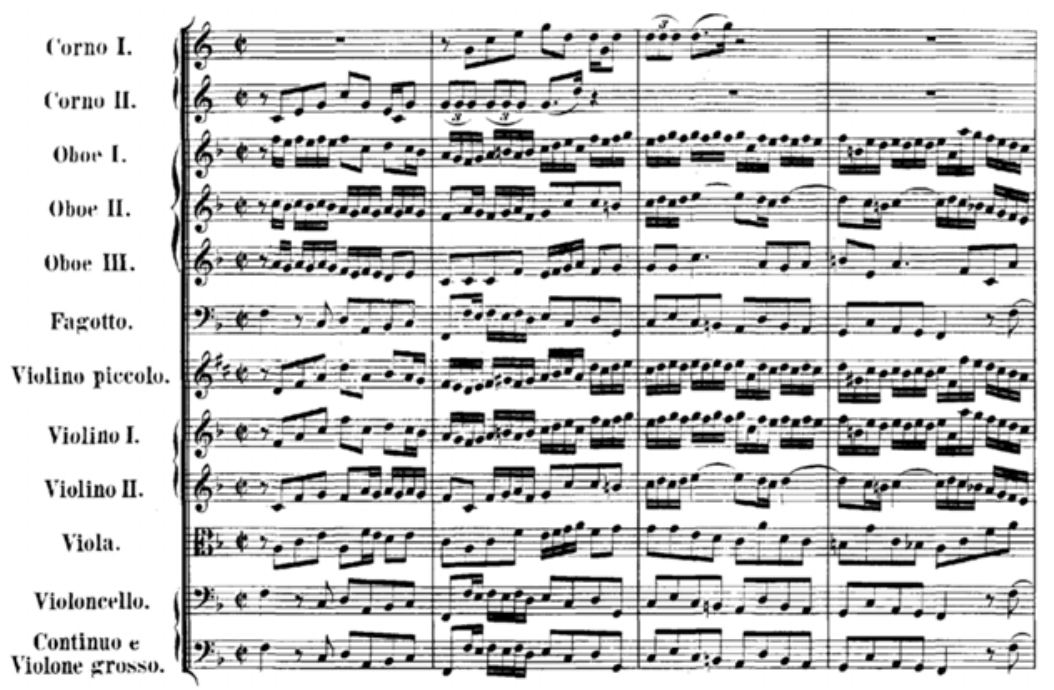

Основной «осевой» пульс восьмыми длительностями в первой части Первого Бранденбургского концерта И.С. Баха 
контрастирует с триолями восьмых валторн. Учитывая специфический довольно резкий тембр барочных валторн, можно сделать вывод, что Бах осознанно и целенаправленно обостряет ритмический контраст между квартолями шестнадцатых у струнных и деревянных духовых и триолями у валторн. Этот прием встречается в этой части исключительно в партии валторн и обостряет значение осевой пульсации для барочной музыки как основополагающий принцип внутренней организации музыкальной ткани (что косвенно подтверждает вышеназванные непрерывность, необратимость, направленность музыкального времени).

Наличие опорного по своей функции баса на первую долю первого такта (здесь: звук «фа») в целом характерно для музыки Баха. Основной же полифонический по своей природе материал данного фрагмента первой части концерта изложен во всех остальных голосах.

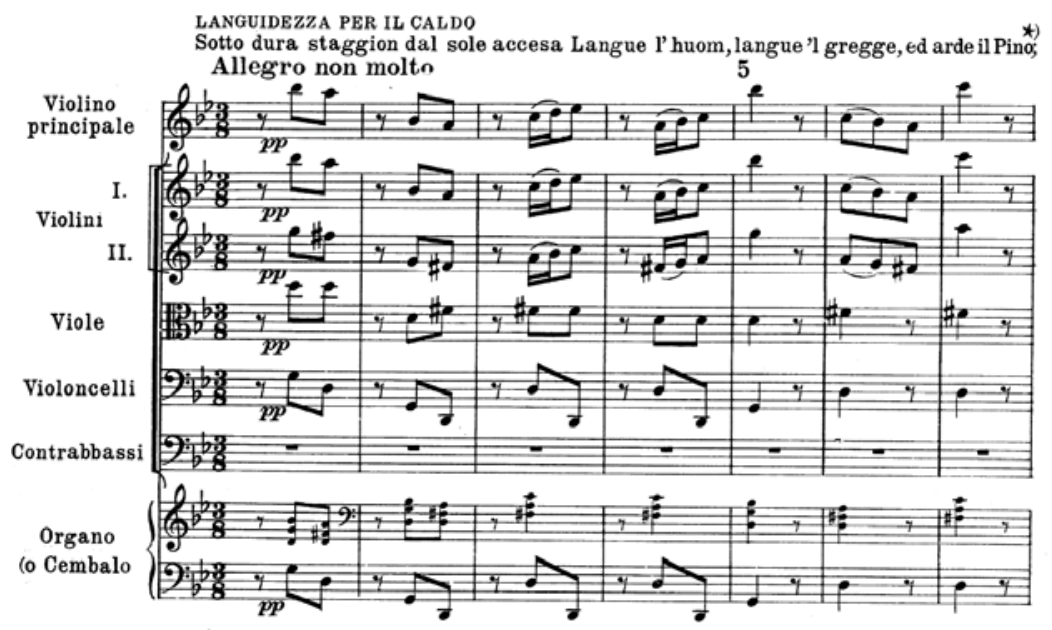

Проблему «незвучащего» в музыке могут наглядно репрезентировать первые такты второго концерта из цикла «Времена года» А. Вивальди. Несмотря на то, что это произведение является одним из самых известных сочинений эпохи барокко, этот фрагмент исполняется таким образом, что создаётся впечатление, что первый вертикальный аккорд приходится на первую долю $3 / 8$ такта. Однако это противоречит одному из основных принципов регулярного тактирования 
в принципе и системе распределения тяжести (в значении значимости) долей для барочной музыкальной эстетики. В соответствии с этой системой значимость долей распределяется по принципу ее (значимости) уменьшения с каждой последующей долей. В качестве незвучащей структуры здесь выступают восьмые паузы первых четырех тактов первой фразы. Этим самым обнаруживается необходимость «внутреннего» исполнения указанной паузы, без которого исполнение этого эпизода приводит к иному, не верному художественному наполнению.

В целом, сушествует большое количество примеров произведений с аналогичным принципом «первоначального импульса», в которых импульс выражен через паузу.

Выскажем предположение, что, в определенной степени, любое музыкальное произведение имеет виртуальную [14, с. 3] форму или является «незвучащим» - и до, и в ghjwtcct? и после своего исполнения. При этом эта виртуальная форма является парадоксально реальной. Для подтверждения этого предположения вспомним идею интенциональности сознания, выдвинутой Ф. Брентано и впоследствии развитой Э. Гуссерлем, согласно которой интенциональность, как фундаментальное свойство сознания, обеспечивает нашу связь с «внешним», отличным от нашего внутреннего «Я», миром, а бытие находится не «где-то», а в нашем сознании. Основываясь в равной мере на этой теории, а также на идее виртуальности (продукте сознания исполнителя) музыкального времени, мы вправе говорить о реальности существования упомянутых незвучащих структур музыки. Суммируя вышеприведенные размышления, можем назвать первоначальный импульс приведённых примеров искомой незвучащей структурой.

Подводя итоги, можно сделать вывод о незвучащих струкmурах как об ином, скрытом даже для опытных исполнителей, принципиально отличаюшемся от явного, уровня экзистенции музыки. Незвучащие структуры, являясь неотъемлемой частью музыки, подобно темной материи космоса, реально существуют и обнаруживаемы лишь по косвенным признакам. Они составляют основу и непосредственно влияют на музыкально-исполнительский процесс и процесс восприятия музыки. «Незвучашее» - время-пространственная основа музыки. 


\section{СПИСОК ЛИТЕРАТУРЫ}

1. Аркадьев М. Фундаментальные проблемы музыкального ритма и «незвучащее». LAP LAMBERT Academic Publishing, 2012. 398 c.

2. Баранова С. Пространство и время в музыке. Омский научный вестник. 2007. № 6. С. 196-194.

3. Бергсон А. Творческая эволюция. Материя и память. Минск : Харвест, 1999. 1404 с.

4. Гуссерль Э. Парижские доклады / пер. и примеч. А. Денежкина. Логос. 1991. № 2. С. 6-30.

5. Лосев А. Музыка как предмет логики. Из ранних произведений. Москва : Правда, 1990. 656 с.

6. Пигалев А. Время культуры. Культурология XX век : словарь. Санкт-Петербург : Университетская книга, 1997. С. 130-134.

7. Пригожин И. От существующего к возникающему. Москва : Наука, 1985. 313 с.

8. Самойленко А. Время или пространство музыки: полемические аспекты музыкальной темпоральности. Київське музикознавство. Киев, 2007. С. 11-37.

9. Суханцева В. Категория времени в музыкальной культуре. Киев : Лыбидь, 1990. 183 с.

10. Харлап М. Ритм и метр в музыке устной традиции. Москва : Музыка, 1986. 103 с.

11. Apel W. The notation of Polyphonic music 900-1600. The medieval academy of America. 1942. $462 \mathrm{p}$.

12. Bonus A. The metronomic performance practice: a History of Rhythm, Metronomes and the mechanisation of Musicality : Doctor's thesis. Department of Music CASE WESTERN RESERVE UNIVERSITY. 2010. 597 p.

13. Botelho M. Rhythm, meter, and phrase: Temporal structures in Johann Sebastian Bach's concertos : Doctor's dissertation. The University of Michigan. 1993. $233 \mathrm{p}$.

14. Kramer J.D. The time of Music. New York : Schirmer books, 1988. $511 \mathrm{p}$. $415 \mathrm{p}$.

15. Langer Susanne. Feeling and form. New York : Scribners, 1953.

\section{REFERENCES}

1. Arkadiev, M. (2012) Fundamental problems of musical rhythm and "non-sounding" [in Russian].

2. Baranova, C. (2007) Space and time in music. Omskiy nauchnyi vestnik, 6, 196-194 [in Russian].

3. Bergson, A. (1999) Creative evolution. Matter and memory. Minsk [in Russian].

4. Husserl, E. (1991) Paris reports. Moscow [in Russian].

5. Losev, A Music as a subject of logic. From the early works. Moscow [in Russian]. 
6. Pigalev, A. (1997). Time of culture. Cultural studies of the twentieth century. Vocabulary. St. Petersburg [in Russian].

7. Prigogine, I. (1985) From the existing to the arising. Moscow [in Russian].

8. Samoylenko, A. (2007) Time or space of music: polemic aspects of musical temporality. Kyiv Musicology, 11-37 [in Russian].

9. Sukhantseva, V. (1990). The category of time in musical culture. Kyiv [in Russian].

10. Harlap, M. (1986) Rhythm and meter in music of oral tradition. Moscow: [in Russian].

11. Apel, W. (1942) The notation of Polyphonic music 900-1600. Massachusetts: The medieval academy of America [in English].

12. Bonus, A. (2010) The metronomic performance practice: a History of Rhythm, Metronomes and the mechanisation of Musicality. PhD thesis. Department of Music Case Western Reserve University [in English].

13. Botelho, M. (1993) Rhythm, meter, and phrase: Temporal structures in Johann Sebastian Bach's concertos. Doctor's thesis. The University of Michigan [in English].

14. Kramer, J. (1988) The time of Music. Schirmer books. New York [in English].

15. Langer Susanne. (1953) Feeling and form. New York [in English]. 